\title{
Globe
}

Revue internationale d'études québécoises

\section{Irène Oore et Oriel C.L. MacLennan : Marie-Claire Blais. An annotated bibliography, Toronto, ECW Press, 1998, 159 p.}

\section{Pamela Lipson}

Volume 1, numéro 1, 1998

URI : https://id.erudit.org/iderudit/1000132ar

DOI : https://doi.org/10.7202/1000132ar

Aller au sommaire du numéro

Éditeur(s)

Globe, Revue internationale d'études québécoises

ISSN

1481-5869 (imprimé)

1923-8231 (numérique)

Découvrir la revue

Citer ce compte rendu

Lipson, P. (1998). Compte rendu de [Irène Oore et Oriel C.L. MacLennan :

Marie-Claire Blais. An annotated bibliography, Toronto, ECW Press, 1998, 159 p.]

Globe, 1(1), 126-127. https://doi.org/10.7202/1000132ar d'utilisation que vous pouvez consulter en ligne.

https://apropos.erudit.org/fr/usagers/politique-dutilisation/ 


\section{Irène Oore et Oriel C.L. MacLennan \\ Marie-Claire Blais. An annotated bibliography Toronto, ECW Press, 1998, 159 p.}

Une bibliographie «exhaustive» des ouvres et des critiques portant sur un auteur devrait réussir à faire saisir au lecteur l'envergure de son œuvre, lorsque certains ouvrages urésistent à la classifications en raison de leur hybridité. Marie-Claire Blais, une auteure complexe et prolifique, a pratiqué depuis les années 1950 plusieurs genres littéraires - dont le roman, la poésie et le théâtre. Son style d'écriture, souvent considéré comme avantgardiste, a donné lieu tant à des interprétations traditionnelles qu'à des critiques s'éloignant du courant dominant.

Cette bibliographie, annotée en anglais, est fidèle au plan organisationnel traditionnel établi par la série de la Annotated Bibliography of Canada's Major Authors, mais elle prend une certaine liberté dans sa classification afin d'inclure et de refléter la diversité de l'œuvre de Marie-Claire Blais, des critiques et des interprétations qui s'y rattachent. Cette bibliographie se divise en trois parties : "Euvres de Marie-Claire Blais» (incluant des chapitres de livres, des adaptations de films et de ballets, des pièces de théâtre et des émissions de télévision); et «Matériel biographique de Marie-Claire Blais" (incluant des entrevues publiées et télévisées et des prix littéraires).

La liste des ceuvres de Marie-Claire Blais est exhaustive, excepté pour la section des comptes rendus, où les auteurs expliquent que, étant donné le nombre imposant de textes (environ 1000 ), elles ont dû choisir le quart du corpus. Pour toutes les sections, les auteurs de cette bibliographie s'efforcent de représenter plusieurs perspectives critiques : la presse québécoise du courant dominant, le domaine littéraire canadienanglais, les critiques américaines et européennes, les écrits féministes et gais, et le point de vue de la littérature comparée. Les auteurs se penchent aussi sur les critiques écrites par d'autres 
auteurs du paysage littéraire québécois et canadien (français et anglais) ce qui donne de l'envergure à la bibliographie.

Cet ouvrage constitue un outil valable et original pour les chercheurs qui s'intéressent à l'œuvre de Marie-Claire Blais, tout en ouvrant ce champ de recherche au monde anglophone. Sa présentation, qui s'organise fidèlement autour de l'œuvre et de Marie-Claire Blais, démontre une profonde appréciation de l'originalité de l'œuvre de cette auteure québécoise et favorise la recherche.

Pamela Lipson

Université McGill 